\title{
The Words We Use, the Actions We Take, and the Perceptions We Hold: First-step Assessments to Inform Wellness Curricula and Burnout Prevention Programming
}

\author{
Karen Horneffer-Ginter, PhD ${ }^{1 *}$, Jeffrey Greene, PhD ${ }^{1}$, Lisa Graves, MD', Kristine Gibson, MD', Roger Apple, PhD ${ }^{1}$, \\ Julia Tullio, MD' ${ }^{1}$, Adrienne Kaufman, MD
}

\begin{abstract}
Introduction: In response to concerns about burnout, many medical schools have been initiating wellness curricula and programming. A key to the success of these efforts is having engagement from targeted audiences. Gathering input from these groups regarding preferred lexicon, wellness actions, and perceptions of judgement or guilt around such actions can help in developing and promoting such curricular and programmatic offerings. Engagement is especially important when it comes to the predictors of burnout (e.g., self-care, self-compassion, and emotional self-disclosure).

Methods: Utilizing a focus-group methodology as a preliminary step, medical school faculty and students discussed terms regarding burnout predictors. Thematic analysis using grounded theory was used to analyze transcriptions with the generated preferred terms being incorporated into a follow-up survey. Surveys were completed by 23 faculty, 65 students, 23 residents, and 124 staff $(n=235)$. The survey asked for ranked preferences of lexicon terms, ratings of engagement and importance around wellness actions, perceptions of judgement and guilt around engaging in self-care, and disengagement and exhaustion via the Oldenburg Burnout Inventory.

Results: Overall, results revealed a preference for alternative language (i.e., "personal well-being" ( $p<0.001)$, "being kind to yourself" ( $p<0.001)$, "sharing your feelings" $(\mathrm{p}<0.001)$ ) compared to phrases commonly used in the wellness literature (i.e., self-care, self-compassion, and emotional self-disclosure). Engagement in self-care $(\mathrm{p}<0.001)$, and self-compassion actions $(\mathrm{p}=0.001)$ were inversely correlated with burnout, while perceptions of being judged $(\mathrm{p}<0.001)$ and feeling guilty for self-care $(\mathrm{p}<0.001)$ were positively correlated with burnout.

Conclusion: Incorporating preferred lexicon terms and mitigation factors (correlating with the reduction of burnout) into wellness curricular development is encouraged as a valuable initial step for medical schools and organizations as they reach out to their intended audiences.
\end{abstract}

DOI: $10.18297 /$ jwellness/vol3/iss $1 / 6$

Received Date: June 15, 2020 Revised Date: Oct 3, 2020 Accepted Date: Feb 16, 2021 Publication Date: Feb 25, 2021 Website: https://ir.library.louisville.edu/ jwellness/

Recommended Citation: Horneffer-Ginter, Karen; Greene, Jeffrey; Graves, Lisa; Gibson, Kristine; Apple, Roger; Tullio, Julia; and Kaufman, Adrienne (2021) "The Words We Kaufman, Adrienne (2021) "The Words We
Use, the Actions We Take, and the Perceptions We Hold: First-step Assessments to Inform Wellness Curricula and Burnout Prevention Programming," Journal of Wellness: Vol. 3 : Iss. 1, Article 6.

Affiliations: 'Western Michigan University Homer Stryker M.D. School of Medicine

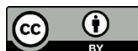

\section{INTRODUCTION}

Concerns regarding rates of physician burnout and depression [1] have been given increasing attention in recent years given the impact these symptoms have on physicians themselves, as well as patient care [2]. In 2014, more than half (54.4\%) of U.S. physicians reported experiencing at least one symptom of burnout [3], and while these rates have shown improvement in recent years (lowering to $42.9 \%$ in 2017 [4]), concerns still remain and the number of institutions allocating resources toward burnout prevention and wellness efforts appears to be on the rise [5]. Along with addressing physicians' greater likelihood of developing "burnout syndrome" (exhaustion, depersonalization, and reduced personal accomplishment) [6], research has also addressed the specific burnout risks for medical students [7], medical faculty [8], and medical school staff [9].

Recent scholarly work has highlighted the importance of addressing burnout with multi-faceted organizational strategies [10-12]. Similarly, a growing body of outcomes research points to the utility of such curricula programming $[13,14]$. Adopting a tripartite approach that considers the synergistic factors pertaining to culture, efficiency of practice, and personal resilience has received particular attention [15]. While these encouragements are useful and justified, a key factor that has yet to be addressed is how best to present such

${ }^{*}$ Correspondence To: Karen Horneffer-Ginter

Email: karen.horneffer-ginter@med.wmich.edu curricula and programming to ensure adequate participation from targeted audiences. Without such engagement, even medical schools and organizations that heed the call to hire a chief wellness officer [5] run the risk of seeing limited utilization of their wellness and burnout prevention programs compared to the rate of their implementation. Central to the idea of engagement is the issue of acceptability (i.e., the need to craft curricular and programmatic offerings in a way that is perceived at both an emotional and cognitive level as relevant, appealing, appropriate, and effective) [16].

One important aspect of acceptability is the use of language that is compelling to the intended audience [17]. As marketing science shows, behavior derives largely from the level of appeal one ascribes to what is being offered, which in large part is influenced by word choice $[18,19]$. Lexicon, then, is a powerful factor for influencing people to consider taking action. Along with being examined within medical humanism [20], a similar point was raised by Arnold et al. [21] in the context of communication curricula. Their encouragement, "...having the members of an educational community share responsibility for creating a lexicon may increase their investment in it and motivation to use it."

As Bohman et al. [15] suggest, a paradigm shift is needed to reject the "historic 'iron doc' culture" in medicine, which 
discounts self-care. This suggestion seems especially timely given the finding that $40 \%$ of physicians report reluctance to seek health care for treatment of a mental health condition [22]. While, in large part, this is due to concerns regarding repercussions for medical licensure [23], the situation is likely exacerbated by the misconceptions that self-care and patient care are "competing interests" [15]. These authors highlight the importance of countering medical cultural norms that characterize self-care as selfish and point out that physicians are more likely to attend to their own personal resilience when they are "embedded in a culture that values and encourages this behavior" [15]. This suggestion is noteworthy when considering that a lack of self-compassion [24] and a presence of self-judgment [25] have been shown to be strong personal domain predictors of burnout. Possibly these findings relate to Berg's two observations that: physicians tend to be reluctant to give themselves credit for their abilities and accolades and tend to handle stress alone and not reach out because they fear looking like an inferior physician [22].

Along with lack of self-compassion being a predictor of burnout, its presence has been found to buffer the positive association between self-criticism and depression for emergency workers exposed to trauma [26]. Training in self-compassion has been found to lead to decreases in anxiety and less use of "expressive suppression" (inhibiting the overt expression of emotion) [27]. This later finding is significant because such inhibition of expression can result in lower social support and less closeness to others [28]. Because 'iron doc' cultural norms may motivate such suppression, fostering learning and practice climates that embrace emotional disclosure, along with self-care and self-compassion, may be key to encouraging individuals to take care of themselves and reach out for help when needed. Such insights are reflected in recent encouragements to offer wellness curricula in both undergraduate $[29,30]$ and graduate medical education [31], that include skill-building around mindfulness, self-compassion [31], and the reflective capacity needed for metacognition and emotional awareness [32].

In the current study, we focused on how best to name the constructs of self-care, self-compassion, and emotional disclosure with all members of our school community given the relevance of these concepts to burnout and the prevalence of 'iron doc' norms within the culture of medicine. Using a mixed-method approach, we identified preferred lexicons, actions taken, and perceptions of guilt / judgment for these topics that were to be included in our wellness curricula and programming. We also included a measure of burnout to consider the possible correlational relationships between actions, perceptions, and reported levels of burnout. Such explorations, we suggest, can not only be used to inform the content of wellness and burnout prevention programming, but also to encourage audiences of both its relevance and potential for creating change in the medical school culture. We hypothesized that,

1. the preferred lexicon at our local institution would differ from the wellness terms most commonly used, and that

2. reported engagement in wellness actions would inversely correlate with reported burnout symptoms.

\section{METHODS}

\section{Part I: Focus Group}

A two-step process, both deemed exempt by our school's $\mathrm{IRB}^{*}$, was used to gather information. First, as a preliminary step, a focus-group methodology was used with a convenience sample of faculty and students who responded to an email inviting them to attend a noon-hour focus group event where lunch was provided. Twelve medical school faculty (6 men and 6 women, each from a different department in our school and ranging in age from 34 to 65) and nine medical students
(4 men and 5 women from the first and second-year classes) each met separately for one hour in an on-campus classroom and were asked to discuss their preferences regarding terms associated with the mentioned burnout predictors. The facilitator guided participants in discussing if each of the suggested phrases was "the best wording" or if "there was a preferable phrase," in relation to each of these prompting questions:

Self-Care (What activities do you do for...?)

Self-Compassion (How do you offer yourself...?)

Disclose your Emotions (How often do you...?)

Difficult Emotions (Are there times when you experience...?)

Sessions were digitally recorded and transcribed so that thematic analysis using grounded theory could be conducted by six of the seven people on the research team. After independently reading through the transcripts, the team met two times in person in order to compare notes. We then communicated by email to ensure convergence on the major and minor themes identified.

\section{Part II: Survey}

All members of our medical school community (135 faculty, 230 residents, 496 staff, and 309 students) were invited by email to participate in an anonymous survey with the incentive of an optional drawing for ten $\$ 25$ gift cards. The survey's content was informed by the focus group findings both in including all suggested preferred terms and by further exploring several themes that emerged. The survey instrument (Appendix A) included several demographic and Likert-scale questions. In addition, participants were asked to rank order their preferred terms of self-care, self-compassion, and emotional disclosure. For each of the three constructs (self-care, self-compassion, and emotional disclosure) participants were asked to rate on a 5-point Likert scale:

"how important" is:

self-care

self-compassion

emotional disclosure to you

"how often" do you:

engaged in activities to support your self-care

extended compassion toward yourself

find ways to share / process difficult emotions when needed

Based on the results from the focus group, participants were asked, on a 5-point Likert scale, "do you ever feel judged for making efforts to take care of yourself" and "do you ever feel guilty for making efforts to take care of yourself."

Each participant was then asked to complete the 16-item Oldenburg Burnout Inventory (OBI) $[33,34]$, which is the measure used by the AAMC in their national survey across medical schools (OBI for medical students). It was chosen for this study because, unlike the Maslach Burnout Inventory, it is based on a two-factor conceptualization of burnout (i.e., disengagement and exhaustion), includes positively and negatively worded items for each factor, and is non-proprietary.

\section{Statistics}

Quantitative analyses were conducted with SPSS (version 25). Along with conducting frequency and descriptive analyses, Chi-Square tests were run to evaluate participants' rank orders of preferred lexicon. For each of the terms, a ChiSquare was run based on the hypothesis that if the commonly used phrase (self-care, self-compassion, emotional disclosure) was generally preferred by participants, over $50 \%$ of respondents would have reported it as their top rank. Friedman non-parametric tests were then run to compare rank order and identify the top three terms ranked for each construct. In addition, Pearson correlation tests were conducted in order to examine the relationships between reports of burnout, wellness actions, and wellness perceptions. 
Table 1: Identified Focus-Group Themes from Most to Least Prevalent \& Example Quotes

\begin{tabular}{|c|c|}
\hline \multicolumn{2}{|l|}{$\begin{array}{l}\text { Category: } \\
\text { SELF-CARE }\end{array}$} \\
\hline Theme & Example quotes \\
\hline $\begin{array}{l}\text { Disliking the term 'self-care' } \\
\text { (both faculty and students) }\end{array}$ & $\begin{array}{l}\text { I don't care for the term so for me it is off-putting. I don't even know what I do for self-care, I think in terms of what do I do to take care of myself (faculty) } \\
\text { Whenever you say self-care, it kind of sounds like it's all on yourself. The self-part I don't know it just sounds like something you need to take on in your extra free time. (faculty) } \\
\text { I generally don't like the word care. It feels judgmental as a person doesn't care } \\
\text { (student) } \\
\text { What I don't like about self-care, it sounds like it has the word selfish in it. And even though I don't think self-care is selfish, that can be misinterpreted that I am just doing this for me and it's not } \\
\text { really going to help anyone else. (student) }\end{array}$ \\
\hline $\begin{array}{l}\text { Feeling guilty for 'self-care' } \\
\text { efforts } \\
\text { (faculty) }\end{array}$ & $\begin{array}{l}\text { Whether I am here or I am home, if I am still working until } 11 \text { o'clock at night and then if I have to do something during the day, my personal life, I will run out and do it, but I feel guilty about } \\
\text { doing that. (faculty) }\end{array}$ \\
\hline $\begin{array}{l}\text { Feeling judged for 'self-care' } \\
\text { efforts } \\
\text { (students) }\end{array}$ & I feel if you're going to ask us what we feel you have to care and do something about it ...There has to be "okay we're going to try to judge you less for taking a personal day. (student) \\
\hline $\begin{array}{l}\text { The need for culture / } \\
\text { organizational change } \\
\text { (both faculty and students) }\end{array}$ & $\begin{array}{l}\text { One of the difficulties of doing something like this is that there's been such an emphasis, there has been so much talk, and yet nothing has changed much (faculty) } \\
\text { The eye rolling is not coming in my mind from those two words put together, it's the fact that it's being pushed over and over again, so I think to a certain extent no matter what you call it you } \\
\text { sort of get the same thing unless you change people's perception about this stuff. (student) }\end{array}$ \\
\hline $\begin{array}{l}\text { Purpose of 'self-care' } \\
\text { activity - to be able to } \\
\text { sustain service to others } \\
\text { (both faculty and students) }\end{array}$ & $\begin{array}{l}\text { I think the general goal people are trying to refer to in discussing self-care is preventing your own degradation. Keeping yourself capable of doing the job you're needing to do. Being the person } \\
\text { you need to be in and out of the work place, in your church and your family. (faculty) } \\
\text { Hearing self-care reminds me of the warning you get on the airplane ... put your own gas mask on first and they have to do that because maternal instinct kicks in, and women try to put their kid } \\
\text { first ... So then that is something I think is lost with the idea of self-care. Because by maintaining yourself and improving your own, you're better meant for any team, you're a better practitioner, } \\
\text { you're a better employee, better person. (student) }\end{array}$ \\
\hline \multicolumn{2}{|l|}{$\begin{array}{l}\text { Category: } \\
\text { SELF-COMPASSION }\end{array}$} \\
\hline Theme & Example quotes \\
\hline $\begin{array}{l}\text { Disliking the term 'self- } \\
\text { compassion,' preferring 'give } \\
\text { yourself a break' other terms } \\
\text { (faculty) }\end{array}$ & $\begin{array}{l}\text { I don't think I have ever encountered self-compassion. First it seems redundant to me. It's very clunky. How do you offer yourself self-compassion. I like the other ones, "give yourself a break." } \\
\text { (faculty) } \\
\text { The first term is probably not as meaningful at the last two; be nice to yourself or give yourself a break. (faculty) }\end{array}$ \\
\hline $\begin{array}{l}\text { Disliking the term 'give } \\
\text { yourself a break' / preferring } \\
\text { 'self-compassion' (students) }\end{array}$ & $\begin{array}{l}\text { I don't love "give yourself a break" just because it feels like you should be constantly working and then every once in a while, you should get this break to be nice to yourself. I think that self- } \\
\text { compassion is something that is more likely continuous, and I think the wording should be represented like that. (student) } \\
\text { As far as give yourself a break, I really don't enjoy it. I hear someone say give yourself a break, it tends to be dismissive and vacuous. It's generally signaled to me that the person is trying to say } \\
\text { something to end the conversation. (student) }\end{array}$ \\
\hline $\begin{array}{l}\text { The importance of letting } \\
\text { oneself be imperfect / having } \\
\text { a supportive culture (faculty / } \\
\text { students) }\end{array}$ & $\begin{array}{l}\text { Allowing yourself to be less than perfect is kind of healthy, unfortunately, we tend to get a pressure cooker, put people in undergrad who can never ever have a misstep. (faculty) } \\
\text { The opposite of self-compassion is perfectionism. You know if I must be perfect then I must beat myself into perfection ... Nobody can sustain that and eventually you crash and burn. (faculty) } \\
\text { Treat yourself the way you would treat others. I think it's generally much easier to say and think very harsh and difficult things about ourselves that we wouldn't say to another person. (student) } \\
\text { I think something that would help with self-compassion and just forgiving yourself for making a mistake would be just to know that other people have made a mistake as well. So, having a culture } \\
\text { of openness about other people have made this mistake and it's not just you. (student) }\end{array}$ \\
\hline $\begin{array}{l}\text { Importance of role-modeling } \\
\text { self-compassion to others } \\
\text { (faculty) }\end{array}$ & $\begin{array}{l}\text { Well, I role model it because I have clinical misadventures and I share those sometimes with residents when it's appropriate- "here I am in this position and yet here's what I have done and I got } \\
\text { through." (faculty) } \\
\text { I periodically screw up fairly royally, and it's usually very publicly, so I get to model certain behaviors and it's actually helpful. So yeah, I'm convinced it can be taught, it just can't be taught "We're } \\
\text { going to talk today about giving yourself a break." (faculty) }\end{array}$ \\
\hline \multicolumn{2}{|l|}{$\begin{array}{l}\text { Category: } \\
\text { EMOTIONAL DISCLOSURE }\end{array}$} \\
\hline Theme & Example quotes \\
\hline $\begin{array}{l}\text { Reasons not to use the term } \\
\text { "emotion" } \\
\text { (faculty) }\end{array}$ & $\begin{array}{l}\text { I don't prefer feelings over emotions, but for some reason emotions always seem to be on the negative side, feelings tend to not. (faculty) } \\
\text { An emotional person might be someone who is happy all of the time, but emotion is a negative thing because you think of somebody who cries all the time, not laughs all the time. (faculty) }\end{array}$ \\
\hline $\begin{array}{l}\text { Pros for the term "emotions" } \\
\text { over "feelings" } \\
\text { (students) }\end{array}$ & $\begin{array}{l}\text { I much prefer emotions to feelings as a term generally. (student) } \\
\text { I prefer emotions as well. I think feelings just is, I don't know it just sounds a little bit childish. I think of Barney or something. (student) }\end{array}$ \\
\hline $\begin{array}{l}\text { Importance of emotional } \\
\text { disclosure / sharing feelings } \\
\text { (faculty) }\end{array}$ & $\begin{array}{l}\text { So I'm used to, when a medical misfortune happened, I've learned what you really need to say is how does that make you feel? How are you dealing with your emotions? (faculty) } \\
\text { I had a colleague once tell me, we will take care of our physical health while avoiding to take care of our emotional or mental health. For me well you could go to the doctor, but that's usually a } \\
\text { physical thing, but when you're emotionally } \\
\text { unwell what do you do? That's just a phrase that has always stuck with me. (faculty) }\end{array}$ \\
\hline $\begin{array}{l}\text { Importance of creating a } \\
\text { work culture that makes } \\
\text { emotional disclosure safe / } \\
\text { Concerns about being } \\
\text { flagged } \\
\text { (faculty and students) }\end{array}$ & $\begin{array}{l}\text { I don't think I would touch that [an offering inviting emotional disclosure] at all. I think my fear of consequence would keep me from attending. (faculty) } \\
\text { As a physician this is a complicated thing because if I disclose that I am feeling really down today, the next thing you know you get referred for a fitness evaluation. (faculty) } \\
\text { It would have to be a cultural shift on mistakes being acceptable and expected. (student) } \\
\text { When I think of emotions, the concept that comes with that is trust... There has to be established amount of trust first. (student) }\end{array}$ \\
\hline
\end{tabular}


Table 2: Chi-Square results comparing participants' top rank-ordered preferred terms with popular terms commonly used

\begin{tabular}{|c|c|c|c|c|c|c|}
\hline \multicolumn{7}{|c|}{ Self-Care } \\
\hline $\begin{array}{l}\text { Top-ranked } \\
\text { preference }\end{array}$ & $\begin{array}{l}\text { Expected N } \\
\text { (Total=234) }\end{array}$ & Expected $\%$ & Observed $\mathrm{N}$ & Observed $\%$ & Chi-Square & $\begin{array}{l}\text { Asymp. } \\
\text { Sig. }\end{array}$ \\
\hline "Self-Care" & 117 & $50 \%$ & 64 & $27 \%$ & $48.02(1,234)$ & $p<0.001$ \\
\hline $\begin{array}{c}\text { Alternative } \\
\text { Terms to "Self- } \\
\text { Care" }\end{array}$ & 117 & $50 \%$ & 170 & $73 \%$ & & \\
\hline \multicolumn{7}{|c|}{ Self-Compassion } \\
\hline $\begin{array}{l}\text { Top-ranked } \\
\text { preference }\end{array}$ & $\begin{array}{l}\text { Expected N } \\
\text { (Total=234) }\end{array}$ & Expected \% & Observed N & Observed $\%$ & Chi-Square & $\begin{array}{l}\text { Asymp. } \\
\text { Sig. }\end{array}$ \\
\hline $\begin{array}{c}\text { "Self- } \\
\text { Compassion" }\end{array}$ & 117 & $50 \%$ & 57 & $24 \%$ & $61.54(1,234)$ & $p<0.001$ \\
\hline $\begin{array}{l}\text { Alternative } \\
\text { Terms to "Self- } \\
\text { Compassion" }\end{array}$ & 117 & $50 \%$ & 177 & $76 \%$ & & \\
\hline \multicolumn{7}{|c|}{ Emotional Disclosure } \\
\hline $\begin{array}{l}\text { Top-ranked } \\
\text { preference }\end{array}$ & $\begin{array}{l}\text { Expected N } \\
\text { (Total=234) }\end{array}$ & Expected \% & Observed N & Observed \% & Chi-Square & $\begin{array}{l}\text { Asymp. } \\
\text { Sig. }\end{array}$ \\
\hline $\begin{array}{l}\text { "Emotional } \\
\text { Disclosure" }\end{array}$ & 117 & $50 \%$ & 17 & $7 \%$ & $\begin{array}{c}170.94(1, \\
234)\end{array}$ & $p<0.001$ \\
\hline $\begin{array}{l}\text { Alternative } \\
\text { Terms to } \\
\text { "Emotional } \\
\text { Disclosure" }\end{array}$ & 117 & $50 \%$ & 217 & $93 \%$ & & \\
\hline
\end{tabular}

Table 3: Overall Top Preferred Terms Ranked for each Construct

\begin{tabular}{|c|c|c|c|c|}
\hline CONSTRUCT & Top-Ranked Preferences & $\begin{array}{l}\text { Mean Rank - } \\
\text { Friedman Test }\end{array}$ & Chi-Square & $\begin{array}{l}\text { Asymp. } \\
\text { Sig. }\end{array}$ \\
\hline \multirow[t]{3}{*}{ SELF-CARE $\rightarrow$} & Personal Well-Being & 2.61 & \multirow[t]{3}{*}{$304.97(5,232)$} & \multirow[t]{3}{*}{$p<0.001$} \\
\hline & Personal Wellness & 2.79 & & \\
\hline & Self-Care & 2.93 & & \\
\hline \multirow{3}{*}{ SELF-COMPASSION $\rightarrow$} & Being kind to yourself & 2.19 & \multirow{3}{*}{$18.92(3.232)$} & \multirow[t]{3}{*}{$p<0.001$} \\
\hline & Self-Kindness & 2.56 & & \\
\hline & Self-Compassion & 2.58 & & \\
\hline \multirow[t]{3}{*}{ EMOTIONAL DISCLOSURE $\rightarrow$} & Share your feelings & 2.85 & \multirow[t]{3}{*}{$229.52(5,232)$} & \multirow[t]{3}{*}{$p<0.001$} \\
\hline & \begin{tabular}{|l|} 
Process your feelings \\
\end{tabular} & 2.86 & & \\
\hline & Process your emotions & 2.97 & & \\
\hline
\end{tabular}

Table 4: Pearson Correlations between Wellness Actions, Perceptions, and OBI Subscales

\begin{tabular}{|l|l|l|}
\hline & Disengagement (OBI) & Exhaustion (OBI) \\
\hline $\begin{array}{l}\text { Engagement in - } \\
\begin{array}{l}\text { Self-Care } \\
\text { Self-Compassion } \\
\text { Emotional Disclosure }\end{array}\end{array}$ & $\begin{array}{l}-0.19(p=0.004) \\
-0.16(p=0.016) \\
-0.10(p=0.13)\end{array}$ & $\begin{array}{l}-0.24(p<0.001) \\
-0.21(p=0.001)\end{array}(p=0.08)$ \\
\hline $\begin{array}{l}\text { Feeling Judged for "making efforts } \\
\text { to take care of yourself" }\end{array}$ & $0.26(p<0.001)$ & $0.28(p<0.001)$ \\
\hline $\begin{array}{l}\text { Feeling Guilty for "making efforts } \\
\text { to take care of yourself" }\end{array}$ & $0.25(p<0.001)$ & $0.39(p<0.001)$ \\
\hline
\end{tabular}

\section{RESULTS}

\section{Part I: Focus Group}

Several themes emerged from the focus groups including a preference for alternative terms, as depicted in the themes and sample quotes listed in Table 1 (previous page). Faculty and students had various reasons for disliking the terms selfcare, self-compassion, and disclosing emotions. All alternative terms suggested were included in the subsequent survey. Other sub-themes that emerged in the conversation involved: (a) feelings of "guilt" and "judgment" (for faculty and students, respectively) for taking time for self-care, (b) the need for cultural/organizational change to support self-care activities and safe emotional disclosure,

(c) the purpose of self-care activities to allow individuals to sustain service to others, (d) the importance of allowing oneself to be imperfect,

(e) role-modeling self-compassion, and

(f) having opportunities for emotional disclosure.

\section{Part II: Survey}

Responses were received from a total of 235 participants: 23 faculty (17\% response rate), 23 residents/fellows (10\%), 124 staff (25\%), and 65 students (21\%). Participants were asked to identify their gender ( $80 \%$ female, $20 \%$ male, $0 \%$ "other"), age range (20-30 [42\%], 31-40 [29\%], 41-50 [11\%], 51-60 [13\%], $61+[5 \%])$, and if English was their native language (94\%). The Chi-Square analysis results indicated that well over $50 \%$ of respondents preferred alternative phrases compared to those commonly used (Table 2). The top three terms, ranked for each construct, are presented in Table 3.

Average total scores (with a possible range of 8-32) and standard deviations were calculated for the Disengagement $(18.45,3.97)$ and Exhaustion $(20.19,4.09)$ subscales on the Oldenburg Burnout Inventory (OBI).

Engagement in self-care and self-compassion actions were inversely correlated with both subscales of burnout, while perceptions of being judged and feeling guilty for self-care were positively correlated with both subscales of burnout. No significant relationships were found between perceptions of importance and burnout across the three constructs.

\section{Table 4.}

\section{DISCUSSION}

Overall, the findings from both the focus group and survey data revealed preferred terms (i.e., "personal well-being," "being kind to yourself", "sharing your feelings") differing from those more commonly used in wellness research (i.e., "self-care," "self-compassion," "emotional disclosure"). As opposed to one preferred wording surfacing for each construct, the variability in preferred terms suggests that there may be value in using multiple approaches to phrasing the titles and descriptions of wellness programming based on the targeted audience. These findings also suggest that a similar process of eliciting feedback regarding lexicon preference may hold similar value at other sites.

In considering the presence of an "iron doc" culture in our local setting, it was notable to see the statistically significant correlations between wellness actions, perceptions of guilt and judgment, and burnout among those who participated in our study. We found that people who engage in self-care actions and who offer themselves self-compassion were less likely to feel disengaged and exhausted. In addition, feeling judged or feeling guilty for making efforts to take care of oneself were correlated with both disengagement and exhaustion.

These findings have offered useful insights regarding how best to promote wellness activities at our school, and they have provided an impetus to address the elements in our school culture that might be contributing to feelings of guilt and judgment for engaging in such activities. This is also the case with some of the themes which emerged in our focus group conversations which have informed agenda items for our leadership and culture workgroups to consider (e.g., the importance of allowing oneself to be imperfect and role-modeling self-compassion).

An important follow-up to this project will be to understand more about how we can support students and employees in tending to their well-being and how incorporating preferred lexicon terms in our educational opportunities can strengthen these efforts.

One step we have taken is to incorporate the suggestions that emerged when framing our wellness curricula and burnout prevention programming. For example, to help increase engagement and acceptability and to minimize the likelihood 
of dissuading targeted audiences, we renamed the "selfcare" curriculum to "personal well-being," and have utilized the term "well-being" in elective offerings for students and announcements for optional "lunch \& learns" and continuing education workshops targeting students, faculty, staff, and residents. We also changed the language in our curricular materials to emphasize the preferred self-compassion and emotional disclosure terms in hopes of creating more openness toward these topics.

We have realized that there may be times when using more preferred and familiar terms in communications, but not in the educational offerings themselves, may be valuable. For example, most of our participants did not care for the term "self-compassion." However, what might get lost with replacing this word is that the definition of self-compassion includes self-kindness, along with mindfulness and an awareness of our common humanity [36].

We found that by exploring lexicon preferences at our school, not only did we gather unexpected input-such as the sub-themes identified in the focus group data-we also generated additional discussion about the nuances of wellness concepts that might otherwise have been overlooked. For instance, in follow up conversations both at our school and with other medical schools, mixed opinions surfaced about other words related to wellness and burnout programming (including "wellness" and "burnout"), which made us aware that we should also be considering more articulate terms in general (e.g., professional fulfillment [24], moral injury [36]) to ensure we're capturing these constructs in ways that remain engaging and not off-putting.

\section{LIMITATIONS}

Both our focus groups involving faculty and students and our subsequent survey, which also included staff and residents, relied on convenience samples. While assessing the lexicon preferences of more engaged members in a community may be viewed as a useful first step, it is possible that those who did not respond to the invitation to participate may have offered different insights and may, in general, be less involved in activities at our medical school. If our sampling had involved equal representation across all groups and demographic variables of interest, this would have allowed for further quantitative comparisons to suggest which factors correlated with varying lexicon preferences. In addition, our study is based on data from only one location. This is both a limitation, but also consistent with the type of setting-focused process we are encouraging at other locations.

\section{CONCLUSION}

The results from our study revealed a preference for alternative terms (i.e., "personal well-being," "being kind to yourself," "sharing your feelings"). In addition, we found that burnout was inversely correlated with engaging in self-care and self-compassion, and positively correlated with feeling judged and feeling guilty for making efforts to take care of oneself. Our findings suggest that there may be value in identifying preferred wellness-related lexicons in one's community as opposed to using only terms from the literature, especially when choosing language to engage target audiences. Demonstrating the local correlations between wellness actions, perceptions of judgment or guilt, and burnout can also be useful in justifying the resources and time required for wellness programming and strengthening the acceptability of these offerings. Such findings can be incorporated into the content and promotion of wellness programs as a means of helping shift unsupportive "iron doc" cultural beliefs that may be present. In sum, we encourage other medical schools and organizations to consider gathering data regarding preferred lexicon, wellness actions, and relevant perceptions as an initial step in creating and promoting well-being programming.

Acknowledgments: The authors wish to thank Rich Brandt, Elizabeth Lorbeer, Amber Turner, and Patrice Mason for their assistance with this project.

${ }^{\star}$ IRB Exempt Ruling: The focus group and survey components of the study were deemed exempt by the Western Michigan University Homer Stryker M.D. School of Medicine's IRB (IRB\#2018-0366/12-3-18; WMed-2019-0447/2-19-19).

\section{REFERENCES}

1. Kane L. Medscape National Physician Burnout \& Suicide Report 2020: The Generational Divide. January 15, 2020. https://www.medscape.com/slideshow/2020-lifestyle-burnout-6012460. Accessed 20 Jan 2020.

2. Bodenheimer T, Sinsky C. From triple to quadruple aim: care of the patient requires care of the provider. Ann Fam Med. 2014 Nov-Dec;12(6):573-6.

3. Shanafelt TD, Hasan O, Dyrbye LN, Sinsky C, Satele D, Sloan J, et al. Changes in burnout and satisfaction with work-life balance in physicians and the general US working population between 2011 and 2014. Mayo Clin Proc. 2015 Dec;90(12):1600-13.

4. Shanafelt TD, West CP, Sinsky C, Trockel M, Tutty M, Satele DV, et al. Changes in burnout and satisfaction with work-life integration in physicians and the general US working population between 2011 and 2017. Mayo Clin Proc. 2019 Sep;94(9):1681-94.

5. Kishore S, Ripp J, Shanafelt T, et al. Making the case for the chief wellness officer in America's health systems: A call to action. Health Aff. 2018 Oct; [cited 2018 Nov 2] https://doi.org/10.1377/hblog20181025.308059.

6. Moss M, Good VS, Gozal D, Kleinpell R, Sessler CN. An official critical care societies collaborative statement: Burnout syndrome in critical care health care professionals: A call to action. Crit Care Med. 2016 Jul;44(7):1414-21.

7. Brazeau CM, Shanafelt T, Durning SJ, Massie FS, Eacker A, Moutier C, et al. Distress among matriculating medical students relative to the general population. Acad Med. 2014 Nov;89(11):1520-5.

8. Dandar VM, Grisby RK, \& Bunton S. Burnout among U.S. Medical School Faculty. Analysis in Brief, AAMC. 19(1) Feb 2019

9. Ewen AM, Gardiner PM, Palma S, Whitley K, Schneider JI. We Matter too: Addressing the wellness of program coordinators in graduate medical education. JCEHP. 2018; 38(3).

10. Brigham T, Barden C, Dopp AL, et al. A journey to construct an all-encompassing conceptual model of factors affecting clinical well-being and resilience. NAM Perspectives Discussion Paper. January 28, 2018.

11. Shanafelt TD, Noseworthy JH. Executive leadership and physician well-being: nine organizational strategies to promote engagement and reduce burnout. Mayo Clin Proc. 2017 Jan;92(1):129-46.

12. West CP, Dyrbye LN, Shanafelt TD. Physician burnout: contributors, consequences and solutions. J Intern Med. 2018 Jun;283(6):516-29.

13. West CP, Dyrbye LN, Erwin PJ, Shanafelt TD. Interventions to prevent and reduce physician burnout: a systematic review and meta-analysis. Lancet. 2016 Nov;388(10057):2272-81.

14. Panagioti M, Panagopoulou E, Bower P, Lewith G, Kontopantelis E, Chew-Graham C, et al. Controlled interventions to reduce burnout in physicians: A systematic review and meta-analysis. JAMA Intern Med. 2017 
Feb;177(2):195-205.

15. Bohman B, Dyrbye L, Sinsky CA, et al. Physician well-being: the reciprocity of practical efficiency, culture of wellness, and personal resilience. NEJM Catal. 2017 Aug.

16. Sekhon M, Cartwright M, Francis JJ. Acceptability of healthcare interventions: an overview of reviews and development of a theoretical framework. BMC Health Serv Res. 2017 Jan;17(1):88.

17. Perloff RM. The dynamics of persuasion: Communication and attitudes in the 21st century. 2nd ed. Mahwah (NJ): Lawrence Erlbaum; 2003.

18. Loken B. Consumer psychology: categorization, inferences, affect, and persuasion. Annu Rev Psychol. 2006;57(1):453-85.

19. Haugtvedt CP, Herr PM, Kardes FR. Handbook of Consumer Psychology. Mahwah (NJ): Lawrence Erlbaum; 2008.

20. Stergiopoulos E, Ellaway RH, Nahiddi N, Martimianakis MA. A Lexicon of Concepts of Humanistic Medicine: Exploring Different Meanings of Caring and Compassion at One Organization. Acad Med. 2019 Jul;94(7):1019-26.

21. Arnold RW, Losh DP, Mauksch LB, Maresca TM, Storck MG, Wenrich MD, et al. Lexicon creation to promote faculty development in medical communication. Patient Educ Couns. 2009 Feb;74(2):179-83.

22. Berg S. 5 Reasons physicians are less likely to seek support. AMA Wire. July 30, 2018.

23. Dyrbye LN, West CP, Sinsky CA, Goeders LE, Satele DV, Shanafelt TD. Medical licensure questions and physician reluctance to seek care for mental health conditions. Mayo Clin Proc. 2017 Oct;92(10):1486-93.

24. Trockel M, Hamidi M, Murphy M, Purpur de Vries P, Bohman B. 2016 Physician Wellness Survey: Full Report. Stanford Medicine WellMD Center; 2017.

25. Montero-Marin J, Zubiaga F, Cereceda M, Piva Demarzo MM, Trenc P, Garcia-Campayo J. Burnout subtypes and absence of self-compassion in primary healthcare professionals: A cross-sectional study. PLoS One. 2016 Jun;11(6):e0157499.

26. Kaurin A, Schönfelder S, Wessa M. Self-compassion buffers the link between self-criticism and depression in trauma-exposed firefighters. J Couns Psychol. 2018 Jul;65(4):453-62.
27. Jazaieri H, McGonigal K, Lee IA, Jinpa T, Doty JR, Gross JJ, et al. Altering the trajectory of affect and affect regulation: the impact of compassion training. Mindfulness. 2018;9(1):283-93.

28. Srivastava S, Tamir M, McGonigal KM, John OP, Gross JJ. The social costs of emotional suppression: a prospective study of the transition to college. J Pers Soc Psychol. 2009 Apr;96(4):883-97.

29. Wasson LT, Cusmano A, Meli L, Louh I, Falzon L, Hampsey M, et al. Association between learning environment interventions and medical student well-being. JAMA. 2016 Dec;316(21):2237-52.

30. Mitchell CM, Epstein-Peterson ZD, Bandini J, Amobi A, Cahill J, Enzinger A, et al. Developing a medical school curriculum for psychological, moral, and spiritual wellness: student and faculty perspectives. J Pain Symptom Manage. 2016 Nov;52(5):727-36.

31. Runyan C, Savageau JA, Potts S, Weinreb L. Impact of a family medicine resident wellness curriculum: a feasibility study. Med Educ Online. 2016 Jun;21(1):30648.

32. Wald HS, Anthony D, Hutchinson TA, Liben S, Smilovitch $\mathrm{M}$, Donato AA. Professional identity formation in medical education for humanistic, resilient physicians: pedagogic strategies for bridging theory to practice. Acad Med. 2015 Jun;90(6):753-60.

33. Demerouti E, Mostert K, Bakker AB. Burnout and work engagement: a thorough investigation of the independency of both constructs. J Occup Health Psychol. 2010 Jul;15(3):209-22.

34. Halbesleben J, Demerouti E. The construct validity of an alternative measure of burnout: Investigating the English translation of the Oldenburg Burnout Inventory. Work Stress. 2005 Jul-Sep;19(3):208-20.

35. Neff K, Germer C. The Mindful Self-Compassion Workbook. New York (NY): Guilford Press; 2018.

36. Dean W, Dean AC, Talbot SG. Why 'Burnout' Is the Wrong Term for Physician Suffering. Medscape Pediatrics. July 23, 2019. 


\section{Appendix A}

Confidential

\section{Survey}

Please complete the survey below.

Thank you!

\begin{tabular}{|c|c|}
\hline $\begin{array}{l}\text { Please select which category best fits your role at } \\
\text { WMed: }\end{array}$ & $\begin{array}{l}\bigcirc \text { Staff } \\
\bigcirc \text { Clinical Physician faculty } \\
\bigcirc \text { Non-Clinical Physician faculty } \\
\bigcirc \text { Non-Physician faculty } \\
\bigcirc \text { Student } \\
\bigcirc \text { Resident/fellow }\end{array}$ \\
\hline Specialty & $\begin{array}{l}\bigcirc \text { Internal Medicine } \\
\bigcirc \text { Pediatrics } \\
\bigcirc \text { Emergency Medicine } \\
\bigcirc \text { Family Medicine } \\
\bigcirc \text { Psychiatry } \\
\bigcirc \text { Surgery } \\
\bigcirc \text { Orthopaedic Surgery } \\
\bigcirc \text { Obstetrics and Gynecology } \\
\bigcirc \text { Medicine-Pediatrics } \\
\bigcirc \text { Other }\end{array}$ \\
\hline Gender & $\begin{array}{l}\bigcirc \text { Female } \\
\bigcirc \text { Male } \\
\bigcirc \text { Other }\end{array}$ \\
\hline Age & $\begin{array}{l}\bigcirc \\
20-30 \\
31-40 \\
41-50 \\
51-60 \\
60-70 \\
71-90\end{array}$ \\
\hline Is English your native language? & $\begin{array}{l}\bigcirc \text { Yes } \\
\bigcirc \text { No }\end{array}$ \\
\hline
\end{tabular}

Please rank order your preferred wording for the term "self-care".

If your preference is not listed here, you can write it in on the last option and rank this as your first choice.

Suggested definition: To take care of oneself; To tend to one's own "mind-body-spirit" health.

\begin{tabular}{lccccccc}
\hline & 1 st & 2nd & 3rd & 4 th & 5 th & 6 th & 7th \\
Self-care & $\bigcirc$ & $\bigcirc$ & $\bigcirc$ & $\bigcirc$ & $\bigcirc$ & $\bigcirc$ & $\bigcirc$ \\
Personal wellness & $\bigcirc$ & $\bigcirc$ & $\bigcirc$ & 0 & $\bigcirc$ & $\bigcirc$ & 0 \\
Personal well-being & $\bigcirc$ & 0 & 0 & 0 & 0 & 0 & 0
\end{tabular}




\section{Confidential}

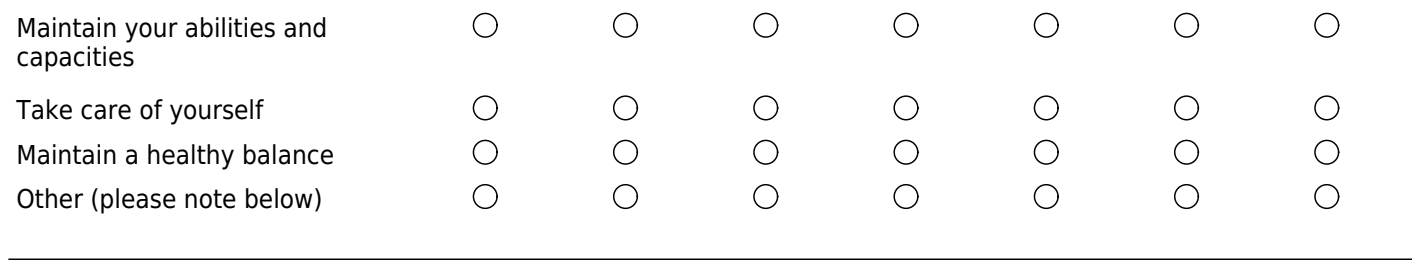

If you chose "Other" above, please note your

preferred wording for the term "self-care."

$\begin{array}{ll}\text { How important is self-care/personal } & \bigcirc \text { Not at all important } \\ \text { wellness/well-being to you? } & \bigcirc \text { Neutral } \\ & \bigcirc \text { Very important }\end{array}$

$\begin{array}{ll}\text { How often do you engage in activities to support your } & \bigcirc \text { Never } \\ \text { self-care/personal wellness/well being? } & \bigcirc \text { Occasionally } \\ & \bigcirc \text { Daily/regularly }\end{array}$

Within the field of medicine, how much encouragement is offered for physician "self-care"?
None
$\bigcirc$
Some
OA
A large degree

Within the field of medicine, how much encouragement is offered for non-physician (clinical and administrative) employee "self-care"?

$\bigcirc$ None
Some
A large degree

Do you ever feel judged for making efforts to take care of yourself?

$\bigcirc$ Never
Occasionally
Daily/regularly

Do you ever feel guilty for making efforts to take care of yourself?

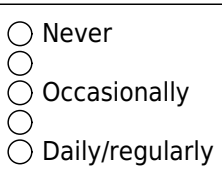

Any comments you'd like to add to explain your responses? 
Please rank order your preferred wording for the term: "self-compassion." If your preference is not listed here, you can write it in on the last option and rank this as your first choice.

Suggested definition: To offer oneself support (especially in difficult times)

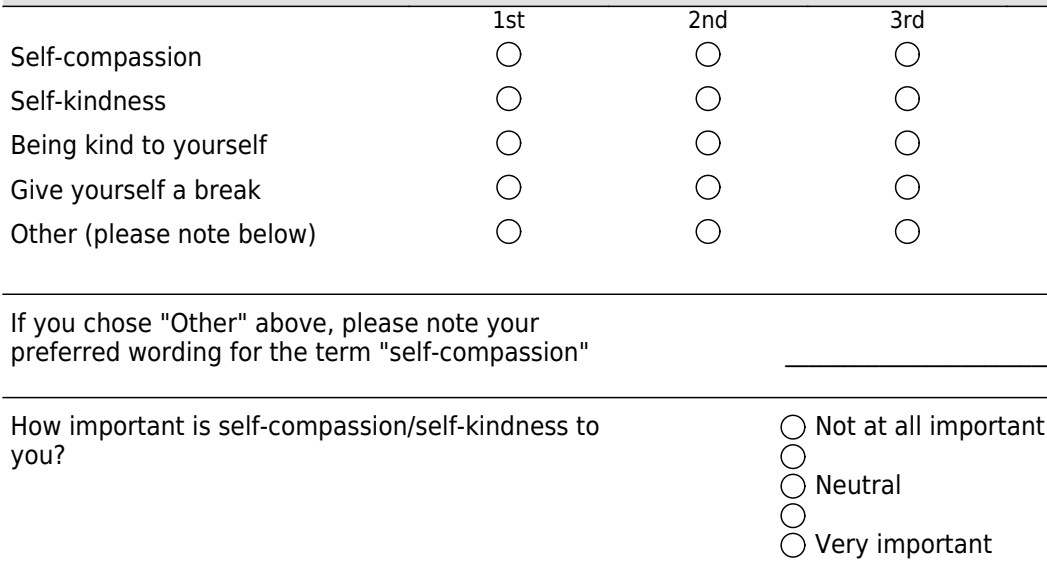

How often do you extend compassion/kindness toward yourself?

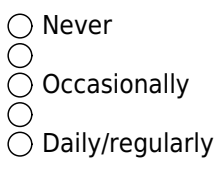

Within the field of medicine, how much encouragement

is offered for physician

self-compassion/self-kindness?

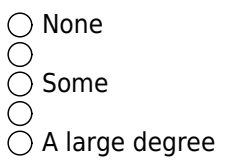

Within the field of medicine, how much encouragement

is offered for non-physician (clinical and

administrative) employee

self-compassion/self-kindness?

\author{
None \\ O \\ Some \\ O \\ A large degree
}

$\begin{array}{cc}\text { 4th } & 5 \text { th } \\ 0 & 0 \\ 0 & 0 \\ 0 & 0 \\ 0 & 0 \\ 0 & 0\end{array}$

Any comments you'd like to add to explain your responses? 


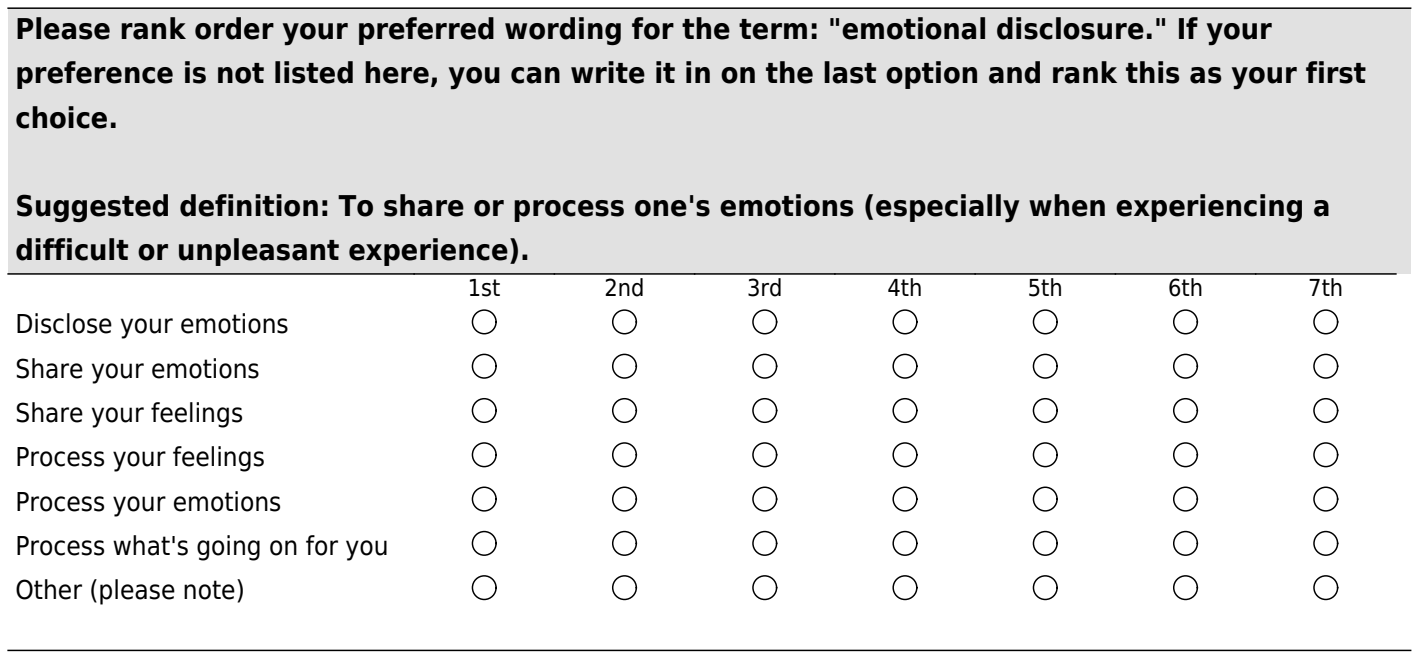

If you chose "Other" above, please note your preferred wording for the term "emotional disclosure."

How important is it to you to have opportunities to share or process unpleasant emotions in difficult times?

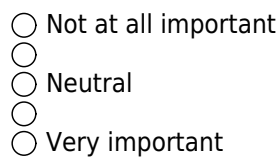

How often do you find ways to share/process difficult emotions when needed?

Within the field of medicine, how much encouragement is offered for physicians

to share or process difficult emotions?

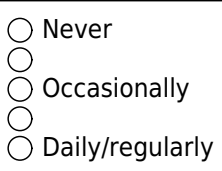

\section{None}

Some

A large degree

Within the field of medicine, how much encouragement

is offered for non-physician (clinical and

administrative) employees to share or process

difficult emotions?

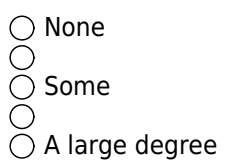

Any comments you'd like to add to explain your responses? 


\begin{tabular}{|c|c|c|c|c|}
\hline & Strongly Disagree & Disagree & Agree & Strongly Agree \\
\hline $\begin{array}{l}\text { I always find new and interesting } \\
\text { aspects in my work. }\end{array}$ & 0 & $\bigcirc$ & $\bigcirc$ & 0 \\
\hline $\begin{array}{l}\text { There are days when I feel tired } \\
\text { before I arrive at work. }\end{array}$ & 0 & 0 & $\bigcirc$ & 0 \\
\hline $\begin{array}{l}\text { It happens more and more often } \\
\text { that I talk about my work in a } \\
\text { negative way. }\end{array}$ & 0 & $\bigcirc$ & 0 & 0 \\
\hline $\begin{array}{l}\text { After work, I tend to need more } \\
\text { time than in the past in order to } \\
\text { relax and feel better. }\end{array}$ & 0 & 0 & $\bigcirc$ & 0 \\
\hline $\begin{array}{l}\text { I can tolerate the pressure of my } \\
\text { work very well. }\end{array}$ & 0 & $\bigcirc$ & 0 & O \\
\hline $\begin{array}{l}\text { Lately, I tend to think less at } \\
\text { work and do my job almost } \\
\text { mechanically. }\end{array}$ & 0 & 0 & 0 & 0 \\
\hline $\begin{array}{l}\text { I find my work to be a positive } \\
\text { challenge }\end{array}$ & 0 & 0 & 0 & 0 \\
\hline $\begin{array}{l}\text { During my work, I often feel } \\
\text { emotionally drained. }\end{array}$ & 0 & 0 & 0 & 0 \\
\hline $\begin{array}{l}\text { Over time, one can become } \\
\text { disconnected from this type of } \\
\text { work }\end{array}$ & 0 & $\bigcirc$ & 0 & 0 \\
\hline $\begin{array}{l}\text { After working, I have enough } \\
\text { energy for my leisure activities }\end{array}$ & 0 & 0 & 0 & 0 \\
\hline $\begin{array}{l}\text { Sometimes I feel sickened by my } \\
\text { work tasks }\end{array}$ & 0 & 0 & O & 0 \\
\hline $\begin{array}{l}\text { After my work, I usually feel } \\
\text { worn out and weary. }\end{array}$ & $\bigcirc$ & 0 & 0 & $\bigcirc$ \\
\hline $\begin{array}{l}\text { This is the only type of work that } \\
\text { I can imagine myself doing. }\end{array}$ & 0 & 0 & 0 & 0 \\
\hline $\begin{array}{l}\text { Usually, I can manage the } \\
\text { amount of my work well. }\end{array}$ & 0 & 0 & 0 & 0 \\
\hline $\begin{array}{l}\text { I feel more and more engaged in } \\
\text { my work. }\end{array}$ & $\bigcirc$ & 0 & 0 & 0 \\
\hline $\begin{array}{l}\text { When I work, I usually feel } \\
\text { energized. }\end{array}$ & 0 & 0 & 0 & 0 \\
\hline
\end{tabular}

If you are interested in being entered into the drawing for ONE of TEN \$25 Panera Gift Cards, please send an email to wellness@med.wmich.edu with the subject heading 'Please enter me in the drawing.'

Please note that entering the drawing is entirely voluntary. 